\title{
HEALTH CARE SPENDING: \\ HISTORICAL TRENDS AND NEW DIRECTIONS
}

\author{
Alice Chen \\ Dana Goldman \\ Working Paper 21501 \\ http://www.nber.org/papers/w21501 \\ NATIONAL BUREAU OF ECONOMIC RESEARCH \\ 1050 Massachusetts Avenue \\ Cambridge, MA 02138
}

August 2015

Research reported here was supported by the National Institute on Aging of the National Institutes of Health under award number P01AG033559. The content is solely the responsibility of the authors and does not necessarily represent the official views of the National Institutes of Health or the National Bureau of Economic Research.

At least one co-author has disclosed a financial relationship of potential relevance for this research. Further information is available online at http://www.nber.org/papers/w21501.ack

NBER working papers are circulated for discussion and comment purposes. They have not been peerreviewed or been subject to the review by the NBER Board of Directors that accompanies official NBER publications.

(C) 2015 by Alice Chen and Dana Goldman. All rights reserved. Short sections of text, not to exceed two paragraphs, may be quoted without explicit permission provided that full credit, including $\odot$ notice, is given to the source. 
Health Care Spending: Historical Trends and New Directions

Alice Chen and Dana Goldman

NBER Working Paper No. 21501

August 2015

JEL No. I1,I11,I12,I13,I18

\begin{abstract}
Over the last five decades, broad changes in the US health care system have dramatically influenced growth in health care expenditures. These structural changes have also influenced the trajectory of the health economics research. This paper reviews some of the seminal health economics papers (measured by citations) and identifies the salient factors driving the growth of medical expenditures. We find that the research identified - and was strongly influenced by - four eras of expenditure growth: (1) coverage expansion; (2) experimentation with financial incentives; (3) the managed care backlash; and (4) a golden era of declining expenditure growth. We conclude by discussing some themes from this research suggesting optimism that, going forward, we can curb excess expenditure growth above GDP growth without harming population health.
\end{abstract}

\author{
Alice Chen \\ Schaeffer Center for Health Policy and Economics \\ University of Southern California \\ 635 Downey Way \\ Los Angeles, CA 90089-3333 \\ alicejc@price.usc.edu \\ Dana Goldman \\ Schaeffer Center for Health Policy and Economics \\ University of Southern California \\ 635 Downey Way \\ Los Angeles, CA 90089-3333 \\ and NBER \\ dpgoldma@usc.edu
}




\section{Introduction}

Unlike any other country in the world, the US spends almost $19 \%$ of its income on health care.$^{1}$ Part of the reason, of course, is that we are one of the richest nations. However, even after adjusting for GDP, the US remains a clear outlier. Figure 1 depicts the relationship between per capita health spending and per capita GDP among 33 OECD countries. 2 Excluding the US, the GDP to healthexpenditure ratio is remarkably linear. Using the trend line for these other countries, one would expect the US to spend $7.7 \%$ of its GDP on health care, 9.3 percentage points less than actual spending. ${ }^{3}$ This health-expenditure differential has almost always existed, and it has only grown larger over time. Figure 2 shows that in 1960, the US spent 1.4 percentage points more of its GDP on health relative to seven other OECD countries. By 2010, this differential had nearly quintupled to 6.8 percentage points.

However, US health care expenditure growth over the last 50 years has not been steady. An examination of growth rates over this period, as shown in Figure 3, suggests growth can be divided into four major eras. The first period, from 1960 to 1981, saw rapid expenditure growth. During this period of expansion, access to health insurance increased, cost sharing fell, and demand grew, as one would expect as prices fell. This effect was also spurred on by rapid but costly technological innovation (e.g., Newhouse (1992). The second era, from 1981 to 1994, is one in which the health expenditure growth rate fell, rose, and fell again. The volatility of health expenditures in this period can be attributed to policy experimentation in provider reimbursement and new benefit designs. Managed care plans skyrocketed in popularity, but by the mid- to late-1990s, interest in managed care fell almost as quickly as it rose. The backlash against managed care contributed to the steady rise in expenditure growth from 1994 to 2002. In 2003, the expenditure growth rate changed course yet again, and this time, its steady 10-year decline culminated in the lowest levels of spending growth since 1960. During this "golden era" of declining expenditure growth, the Congressional Budget Office (CBO) has reduced- every year for the last six years in a row- its estimate of how much the federal government will need to spend on Medicare ( Sanger-Katz \& Quealy, 2014).

In this article, we review the dominant factors responsible for the observed changes in the health expenditure growth rate over time. These factors have heavily influenced the trajectory of health economics research, and they inform the direction for not only future research, but also future policy. For each factor, we discuss the literature's most-cited works, listed in Tables 1 and 2. Certain factors, such as benefit design, socioeconomic factors, and technology, have played a continuous role in shaping health expenditures throughout the last five decades. We introduce those topics at length when discussing the first period and revisit them in subsequent periods. We conclude by considering the innovations in health care structure and delivery that continue to shape the US health care system.

\footnotetext{
${ }^{1}$ Official estimates of health spending in the US are provided by the Centers for Medicare and Medicaid Services' (CMS) National Health Expenditure Accounts. Over $80 \%$ of health care spending is attributed to health care services or goods. Services are provided by physicians, other medical professionals, dentists, home health care, nursing homes, and hospitals; and goods include prescription drugs, other non-durable medical products, and durable medical equipment. Also included are expenditures on public health activities, government administration, the net cost of health insurance, and investments related to health care research.

${ }^{2}$ Luxembourg is omitted from this list.

${ }^{3}$ These figures are based on authors' calculations using 2010 data from the World Bank's World Development Indicators.
} 


\section{Period 1: Coverage Expansion, 1960-1981}

From 1960 to 1981, the growth rate of health expenditures generally trended upwards. During this period, health expenditures rose from less than $\$ 140$ per capita in 1960 to over $\$ 1,000$ per capita in 1980. While part of this growth can be attributed to an increase in personal wealth, GDP per capita merely quadrupled in size, whereas health expenditures per capita increased over seven fold. In addition to an expanding economy, the presence of employer-sponsored health insurance rose, contributing to a higher uptake of insurance, improved access to care, and reduced patient cost-sharing. These changes enabled more people to afford the ground-breaking, yet expensive, medical innovations that were extending life-expectancy and creating a growing aging population.

\subsection{The Spread of Health Insurance}

Due to an increasing demand for health care, improvements in medical techniques and technology, and rising medical fees, the 1930s saw a surge of public interest in health insurance. Hospitalswhich had traditionally limited themselves to providing care- responded by organizing methods for local associations to prepay for services rendered to the community. These prepaid planseventually combined under the auspices of the American Hospital Association and entitled the Blue Cross plans- proliferated across the country, enrolling approximately $20 \%$ of the population by 1947 (Reed, 1947). Observing the success of the Blue Cross plans, commercial insurance companies quickly followed suit, and by the early 1950s, enrollment in commercial policies had overtaken enrollment in Blue Cross plans (Thomasson, 2004). Throughout this period, employers played an important role in the provision of and demand for health insurance. With Truman era wage and price controls, employers had limited freedom to raise wages. As a result, they began to compete for workers through increased fringe benefits.

Federal legislation enacted in the 1940s and 1950s helped spur the spread of employer-sponsored health insurance. These rules culminated with the Internal Revenue Act of 1954, which demarcated employer contributions to employee health insurance plans as non-taxable income. Although the bill was controversial- with some lauding it as being "fortunate for the country" and others contending that it was drafted "to fund campaign pledges"- this piece of legislation cemented the prevalence of employer-sponsored health insurance in the US (Morris, 1954). To this day, the preferential tax treatment of health benefits is one of the largest tax expenditures in the US budget; in 2013, the exclusion of income and payroll taxes from employer and employee contributions total in excess of $\$ 250$ billion in foregone tax revenue (Rae et al., 2014).

By 1960, 68\% of the population carried health insurance. However, Congress and President Lyndon Johnson were concerned that low-income and elderly people had trouble obtaining affordable health insurance and paying for health care, so they created Medicaid and Medicare in 1965. Medicaid, known then as Title XIX, provided federal matching funds for states to finance the health care of individuals who were at or close to the public assistance level. On the other hand, Medicare provided virtually universal public health insurance to individuals aged 65 and older. Medicare Part A provided coverage for up to 90 days of inpatient hospital expenses after an initial deductible; with $25 \%$ co-insurance for days 61 to 90 . Through Part B, individuals received supplementary coverage of physician services, and they were responsible for a $20 \%$ coinsurance. Both programs were intended to integrate care into the mainstream, a goal that was ultimately successful for Medicare- in part due to its universality for the elderly- but not for Medicaid. 
As take-up of both public and private insurance grew, economists began to recognize the potential to over-consume health care services, in a strict welfare sense that the costs of providing additional services exceed patient's willingness-to-pay if uninsured. In seminal papers, Pauly (1968) noted that insurance distorts the price paid by consumers, and Pauly (1974) demonstrated that there will be over-insurance in the presence of imperfect information. Feldstein \& Friedman (1977) provided further insight by modeling demand for health insurance, with the important finding that the tax subsidy for health insurance enshrined in the Internal Revenue Act of 1954 substantially increases health insurance demand. This research led to a crucial insight that would guide health economics to this day: insurance reduces the price to the consumer (cost-sharing), which can lead to increased utilization. When consumers with health insurance demand more care than they would have at normal market prices, the value of their care is less than the market price (Holmstrom, 1979). The difference between the cost to produce care and the lowered value of care to insured consumers represents an inefficiency that generates welfare loss.

While this may seem tautological today, the notion that health care use responded to price was hardly well-established. This motivated one of the best experimental social science studies ever conducted: the RAND Health Insurance Experiment conducted from 1974 to 1982. The experiment sought to identify the effects of health insurance on utilization, costs, and overall health. The experiment, which randomly assigned families to either a prepaid group practice or one of 14 fee-for-service insurance plans, demonstrated that families in the least generous plans spent at least $30 \%$ less on medical care. This responsiveness to price was present in both the outpatient and inpatient care settings, yet - despite the big difference in utilization- there was little or no difference in general health (Manning et al., 1988).

Decades of research has confirmed the findings of the RAND study. Most recently, a similar Oregon Health Insurance Experiment examined the causal effect of cost-sharing on health utilization and health outcomes. Randomizing Medicaid coverage for a group of uninsured low-income individuals, Finkelstein et al. (2012) estimate that having insurance coverage is associated with a $30 \%$ increase in probability of having a hospital admission and a 35\% increase in the probability of having an outpatient visit.

Beyond the RAND and Oregon experimental studies, some quasi-experimental studies and many non-experimental studies provide similar evidence. For example, researchers have used the Massachusetts health reform for universal coverage and the age 65 Medicare cutoff as sources of exogenous variation in insurance coverage (e.g., Card et al., 2008, Kolstad \& Kowalski, 2012). After surveying 923 articles, Goldman et al. (2007) conclude that increased cost-sharing is associated with lower rates of drug treatment, worse adherence among existing users, and more frequent discontinuation of therapy. It should be noted that much of the non-experimental work utilizes geographic variation in cost-sharing, such as state-level changes in Medicaid (e.g., Reeder \& Nelson, 1985, Stuart \& Zacker, 1999). Finkelstein (2007) uses geographic variation in private health insurance coverage prior to Medicare's introduction. She finds that the overall spread of health insurance between 1950 and 1990 may be able to explain about half of the increase in real per capita health spending over that time period. The bottom line from all this research is that we know coverage expansions- both in terms of new insurance and more generous insurance- can explain much of the growth of health care spending during this period. In 1960, out-of-pocket spending constituted $47 \%$ of total health expenditures, and only $67 \%$ of people had health insurance. By 1981, out-of-pocket spending constituted less than $22 \%$ of total health expenditures, and over $85 \%$ of people had health insurance. 


\subsection{Technology and Quality}

Health insurance was not the only factor changing over this period. On the supply-side, expensive new technologies were also entering clinical practice. Between 1960 and 1980, important innovations included major pharmaceuticals-e.g, diuretics (1958), beta blockers (1962), and vaccinations for measles (1963), mumps (1967) and meningitis (1978). Biotechnology engineers also developed mammography imaging (1974), computerized tomography scans (1975), and ultrasounds (1978), and these were quickly adopted into routine patient care. Providers performed the first liver (1962), lung (1963), and heart (1967) transplants and experimented with techniques such as gene splicing (1973) and in-vitro fertilization (1978).

The development and diffusion of medical technology is a subject that is near and dear to health economics. Hall \& Jones (2007) argue that this a consequence of income growth. They use an expected lifetime utility framework to show that expensive medical technologies are valued because of the rising value of life. In their model, a social planner chooses the consumption and health spending for a representative individual so that the individual's utility is maximized subject to resource and health production constraints. As future mortality declines, the value of life increases and the marginal benefit of health spending increases, shifting total spending towards health.

Empirically, measuring the contribution of technology to health-expenditure growth has been difficult as technological change and the demand for health insurance are highly interdependent (Weisbrod, 1991). When previously untreatable conditions become treatable, individuals become more susceptible to higher and more variable health care costs, enhancing the demand for insurance and increasing utilization. Some researchers have attempted to disentangle the role of technology from utilization. For example, Newhouse (1992) notes that from 1950 to 1990, hospital admission rates and lengths of stay did not increase. However, the real cost of a day in the hospital quadrupled, suggesting that technology, as opposed to utilization, drove medical care costs.

More and better technology- and the attendant higher spending- may not be indicative of improved quality of life, increased longevity, or less time away from work (Fisher et al. 2003a b). The value of technology depends on how it affects the medical system (Cutler \& McClellan, 2001). Some technologies allow for the treatment of previously untreatable diseases. Because they expand the treatment possibility frontier, those technologies are generally cost increasing, and their worth will depend on how valuable they are to the marginal patient. Other technologies act as substitutes for older therapies. Replacement therapies are not necessarily cost increasing, but their effectiveness may also vary. Cutler \& McClellan (2001) analyze five conditions: heart attacks, low birth weight infants, depression, cataracts, and breast cancer. They find that in most cases, technological innovations in medicine led to net positive returns, but in the case of breast cancer, the slight increase in outcomes is roughly counterbalanced by the substantial increase in costs. Others use randomized, placebo-controlled trials to identify the returns of technology. For example, Moseley et al. (2002) demonstrate the ineffectiveness of arthroscopic surgeries for patients with osteoporosis, and Temel et al. (2010) shows that palliative care can lead to higher survival rates relative to chemotherapy for patients with terminal lung cancer.

These studies highlight the importance of assessing the appropriateness of medical-technology use. Although randomized clinical trials offer an gold-standard for identifying the effectiveness of medical technologies, they are often time-consuming, expensive, and particular to a narrowly defined group of patients. Proposed by Brook et al. (1986), an alternative is to synthesize expert 
opinions through surveying panelists and categorizing their ratings. Differences among panelists can indicate evenly balanced benefits and risks of doing a procedure or disagreements over what the benefits and risks are. Regardless of the source of controversy, disagreements can account for much of the observed differences in medical spending across the country. Phelps \& Mooney (1993) find that disagreements among physicians and their patients account for more of the observed variation in health spending than differences in socioeconomic factors. Baicker \& Chandra (2004) conclude that states with higher Medicare spending have lower-quality of care, perhaps because costly, intensive care crowds out the use of more effective care, and Finkelstein et al., 2014 show that supply-side differences may also account for up to $50 \%$ to $60 \%$ of the geographic variation in health care utilization.

\subsection{Socioeconomic Factors}

Even absent technological change, health expenditures will rise due to the changing demographics in the US. Over the last five decades the average American has became richer, more educated, and older. The effects of income are well-established: when income increases, the demand for both health insurance and health care increase. Liu \& Chollet (2006) review the literature, and they conclude that the income elasticity of demand for health insurance is about 0.1 . Although this elasticity is small, changes in income have a larger effect on the type and generosity of health plan chosen, as opposed to the intramarginal decision to purchase insurance (Ringel et al., 2002). The estimates for the income elasticity of demand for health care range from 0.0 to 0.2 , suggesting that health care is a normal good. Other studies that use time-series or aggregated state- or county-level data have produced higher estimates, ranging from 0.2 to 1.5. As Figure 1 suggests, income elasticities in other countries are higher, and cross-national studies have estimated income elasticities ranging from 1.15 to 1.31 (e.g., Newhouse, 1977).

When relying on income elasticities to forecast changes in demand, it is worth noting that few studies observe exogenous changes in patient income. Because nearly all studies use observational data, these elasticities are measured as differences in demand attributable to differences, rather than changes, in income. Furthermore, the income elasticity may depend greatly on the service considered: certain services are necessities and will be fairly income-inelastic. Other services, such as cosmetic surgery, are discretionary and may be quite income-elastic.

The link between education and the demand for health services is more nuanced but perhaps even more important. As Grossman (2000) explains, the theoretical relationship between education and health demand is unclear. Education makes a person more efficient in producing health, so the quantity of health care required to achieve a given health stock is lowered. At the same time, education increases the demand for health, so the overall relationship between education and health depends on the increased productivity of inputs relative to the outward shift in demand for health care.

There is a well-established positive correlation between education and health, but identifying a causal relationship- and understanding why it is exists- has proven more elusive. Cutler \& Lleras-Muney (2008) review the literature. Relying on studies that use quasi-experimental variation on schooling policies, they conclude that part of the correlation between education and health is causal. Partial explanations for the relationship between education and health include the higher educated having higher income, greater access to health care, better labor market outcomes that provide health insurance and safer working environments, and a heightened sense of control and 
self esteem through having a higher rank in society. More tenuous explanations include the higher educated placing higher valuations on future life years, being less risky, having access to more health-related information, having improved critical thinking skills, and having wider social networks.

Coupled with medical innovations, higher income and more education lead to improvements in health that generate large increases in longevity. In 1960, average life expectancy at birth was 69.7 years. By 1980, it was 73.7 years, and- by 2010- had reached 78.7 years. ${ }^{4}$ The cumulative gains in life expectancy from 1970 and 2000 have added about $\$ 3.2$ trillion per year to national wealth, and the reduced age-specific mortality rates have mitigated expenditure growth prior to end-of-life care. However at the same time, a growing aging population has increased health expenditures. Cutler et al.(2006) show that the incremental costs per year of life gained has increased disproportionately for those ages 65 and over, due in part to the increased utilization of Medicare-covered home health care and hospice services. Even though the reliance on non-hospital services has grown, the use of hospital services at the end-of-life has not slowed appreciably. Assuming constant spending per age, Newhouse (1992) estimates that the changing population of those over 65 account for about $15 \%$ of the increase in total spending in the late 1980s. Spillman \& Lubitz (2000) further demonstrate that both total expenditures from age 65 to death and spending in the last two years of life increase with longevity.

\section{Period 2: Policy Experimentation, 1981-1994}

By the 1980s, health expenditures were increasing at an all-time high of $16 \%$ a year. But in 1981, and again in 1984 and 1991, the growth rate of health expenditures fell significantly. Table 3 lists the ten largest declines in annual health expenditure growth rate from 1960 to 2015. Significantly, five of the six largest declines in the health expenditure growth rate occurred during this period. We see health-expenditure growth falling, then rising, then falling again-a pattern that may be explained by innovation in insurance contracts and financial incentives.

The initial decline in health expenditures from 1981 to 1983 remains relatively understudied. The recession which began in July 1981 and ended in November 1982 played a key role. Between 1981 and 1983, the growth rate of personal health care expenditures, accounting for approximately $85 \%$ of national health expenditures, fell by almost 6 percentage points. The decline affected all aspects of spending, including an 8.6 percentage point reduction in hospital expenditure growth, 5.1 percentage point reduction in physician and clinical expenditure growth, and a 10 percentage point reduction in dental service expenditure growth. Such slowing of expenditures is consistent with studies finding a pro-cyclical relationship between health and recessions (Charles \& DeCicca 2008, Dehejia \& Lleras-Muney 2004, Ruhm 2000). Researchers have noted that people tend to engage in healthier behaviors during recessions, for example, by increasing exercise, reducing smoking and drinking, and lowering the consumption of sugary drinks (Asgeirsdottir et al. (2014), Catalano et al. (2011), Ruhm \& Black (2002)). Gibson et al.(1984) attribute any remaining growth in health expenditures to price inflation. Because health-related goods and services tend to be labor intensive, they conclude that price inflation is likely higher in health care than it is in other

\footnotetext{
${ }^{4}$ The data is from Table 22 of Health, US, 2011, CDC <http://www.cdc.gov/nchs/hus/contents2011.htm>. Accessed August 1, 2015.
} 
industries. However, other factors were at play as providers and payers experimented with other models.

\subsection{Medicare Payment Reform}

\subsubsection{The Prospective Payment System}

Another precipitous decline occurred from 1984 to 1986, and it aligns closely with the October 1983 implementation of Medicare's prospective payment system (PPS). Under PPS, hospitals are reimbursed at a per-determined rate per inpatient admission, regardless of actual services administered. Clinical information is used to classify each patient into a diagnosis-related group (DRG), and each DRG has a payment weight associated to it. The weights are based on the average resources needed to treat a Medicare patient with a specific diagnosis. In theory, PPS incentivizes hospitals to use resources efficiently, especially if a given provider tends to incur higher than average costs. The extensive empirical literature supports this theory, and Coulam \& Gaumer (1992) provides a comprehensive review.

Financially, the evidence points to reductions in total margins and a slower rate of increase of hospital expenditures (Feder et al., 1987, Hadley et al., 1989). The reduced hospital expenditures can be attributed to a slowdown in the increase in wages per hour, improved labor productivity, and moderate, short-lived reductions in the length of stay (e.g., Cromwell \& Pope, 1989. Long et al., 1987). PPS also shifted the setting in which care is administered. Physicians shifted a share of their surgical procedures from the inpatient setting to the outpatient setting, where payments were made according to a fee-for-service (FFS) model (DesHarnais et al., 1988, Sloan et al., 1988). Hospitals also increased the proportion of patients they discharged to home health agencies (e.g., Long et al., 1987). In theory, discharges to skilled nursing facilities should also have increased, but the empirical evidence is mixed. The conflicting findings are likely due to concurrent changes in coverage and payment policies for skilled nursing facilities during this period.

While PPS appears to have lowered costs, it can come at the expense of cost-shifting, creamskimming behavior, or lower quality of care. Reimbursements are benchmarked to the cost of treating the average patient, so in theory, PPS can encourage hospitals to avoid treating the sicker, costlier patients. It can also encourage hospitals to discharge patients as early as possible, regardless of potential increases in health risk. However, there are no clear empirical documentations of these adverse behaviors. Prices to third-party payers did not increase, suggesting that hospitals did not shift Medicare PPS shortfalls to private payers (Hadley \& Zuckerman, 1990, Zuckerman \& Holahan, 1988). Mortality statistics and remission rates did not change substantially, and transfers, which allows for the "dumping" of sicker patients to other hospitals, also did not change (e.g., Kahn et al., 1990, Sloan et al., 1988).

There is stronger evidence that PPS encouraged upcoding or DRG creep, which refers to the manipulation of diagnostic coding to maximize reimbursements. Identifying DRG creep is difficult because some changes in case mix are related to true changes in the resources needed care for sicker patients (e.g., Ginsburg \& Carter, 1986). Each year, the Center for Medicare and Medicaid Services (CMS), formerly known as the Health Care Financing Administration (HCFA), uses data on the average hospital costs to recalibrate weights for DRGs. Therefore, an increase in DRG weights can be indicative of either upcoding or simply the need to perform more complex, technologically intensive procedures that cannot be conducted outside of a hospital. Two studies 
overcome these empirical challenges. Carter et al. (1990) exploit data from a private firm that independently recoded DRGs for a random sample of hospital charts. They find that between 1986 and 1987, about two-thirds of the change in DRG payments reflect actual changes in the complexity of cases, while the rest can be attributed to changes in coding practice. Dafny (2005) utilizes an exogenous increase shock to certain DRG codes to identify the tendency to upcode. In 1987, HCFA eliminated several DRG codes and recalibrated the DRG weights. The recalibration created differential price changes among highly substitutable pairs of DRG codes. Dafny finds that hospitals respond primarily by upcoding patients to diagnosis codes with the largest price increases.

Despite the wealth of studies looking at PPS, several empirical constraints limit our understanding of the potential effectiveness of PPS as a cost-containment strategy. First, the national adoption of PPS lends itself to a pre- and post-PPS study, but such an approach cannot disentangle the impact of PPS from temporal confounding factors (Giacalone, 2001, Lohr, 1990). For example, the increasing adoption of technology favored use of outpatient care. The rise of managed-care programs contributed to cost-reductions, and the liberalization of home health agencies from restrictive Medicare rules increased the appeal of home health care. The 1986 amendments to the Conditions of Participation, which laid forth new quality assurance standards for hospitals, also likely dampened potential quality-reductions from to PPS. Second, many studies focus on only the first three to four years following PPS implementation, so behavioral changes are limited to shortrun observations. Third, it is widely conceded that in the first year of PPS, the "overpayment" created margins that were aberrant, making the short study windows even more limiting. Nevertheless, policymakers consider PPS to be a successful method of containing costs, and the system was later implemented for Medicaid and Medicare reimbursements in skilled nursing facilities in 1997 and home health agencies and Federally Qualified Health Centers in 2000.

\subsubsection{The 1985 and 1987 Legislative Changes}

From 1986 to 1988 , the health expenditure growth rate once again began to climb. The literature examining this brief rise remains scant. However, it is likely not coincidental that the three health service groups with the largest expenditure growth rates in this period-Medicare services, home health services, and other professional services- are those that were most highly targeted by major federal policy changes.5 In 1985, the Reagan administration passed the Consolidated Omnibus Reconciliation Act of 1985, and in 1987, they passed the Omnibus Budget Reconciliation Act of 1987.

Both reforms mandated increases in the Medicare payment rate for inpatient hospital services. The 1985 act increased inpatient payments by $1 \%$, and the 1987 act increased inpatient payments by $3 \%$ for rural hospitals, $1.5 \%$ for hospitals located in large urban areas, and $1 \%$ for all other hospitals. The 1987 act also increased the medical economic index for physician services by $3.6 \%$ for primary care services and $1 \%$ for all other services. These payment increases likely incentivized providers to perform more services.

Both mandates also targeted home health care and other professional services. For example, Medicare home health agencies became required to provide services through licensed health care

\footnotetext{
${ }^{5}$ The annual growth rate of Medicare expenditures went from $7 \%$ in 1986 to $13.7 \%$ in 1989. For home health services, the annual growth rate of expenditures went from $13 \%$ in 1986 to $26.5 \%$ in 1988. For other professional services, the annual growth rate of expenditures went from $14 \%$ in 1986 to $21 \%$ in 1988 . These figures are calculated using data from the National Health Expenditures Account.
} 
professionals and were subject to unannounced quality check-ups. Medicare also became required to financially cover outpatient occupational therapy services, services provided by optometrists, and services furnished by select clinical social workers. These increases in benefit coverage likely incentivized a higher utilization of services. Although increases in the home health and professional service expenditures were large, these services account for only 1.1 to $1.6 \%$ of national health expenditures. Changes in hospital and physician payments likely constitute a much larger explanation for the increasing health expenditure growth rate during the late 1980s.

While certain Medicare payments increased, others were reduced. These include payment reductions for indirect medical education costs, reductions in the prevailing charges for 12 commonly performed procedures, and freezes on the fee schedules for clinical diagnostic laboratory testing.$^{6}$ The 1987 act also reduced payments for durable medical equipment, prosthetics, and orthotics to the lower of the actual charge for the equipment or the fee schedule amount established by the carrier. This payment change for durable medical equipment foreshadows the 2013 movement towards competitive bidding; under the competitive bidding program, suppliers submit bids to provide equipment and supplies at lower prices than what Medicare currently pays.

\subsubsection{The 1989, 1990, and 1993 Legislative Changes}

Following its brief increase, the health expenditure growth rate began to decline once again in the 1990s. While most of the decline can be attributed to the rise of managed care (discussed in Section 3.2), the repeated reductions in Medicare payments also played a role. The 1990s were marked by Medicare payment reductions with the explicit goal of reducing the deficit. The Omnibus Budget Reconciliation Acts of 1989, 1990, and 1993 resulted in annual reductions in Medicare payments from 1991 through 1997. Together with the implementation of PPS, these reforms were estimated to have reduced Medicare payments by $\$ 160$ billion. The reductions in hospital payments from Medicare, known as Medicare "bite," had differential impacts during the late 1980s and early 1990s. Cutler (1998) notes that in the 1980s when PPS was first introduced, Medicare payments were offset by increased prices to private insurers. However, when managed care networks grew, it became more difficult to shift costs from the public sector to private payers, so hospitals were forced to reduce costs by downsizing.7

\subsection{Managed Care}

One of the most important policy experiments involved managed care. Managed care plans, a term broadly used to describe health insurance contracts aimed at reducing costs while improving quality of care, began to gain in popularity in the 1980s. These plans included models such as health maintenance organizations (HMOs), preferred provider organizations (PPOs), point of service plans, and exclusive provider organizations. They are differentiated by the amount of outof-network coverage offered and whether gatekeepers are used to access specialized care. While

\footnotetext{
${ }^{6}$ The 12 commonly performed procedures include bronchoscopy, carpel tunnel repair, cataract surgery, coronary artery bypass surgery, diagnostic and/or therapeutic dilation and curettage, knee arthroscopy, knee arthroplasty, pacemaker implantation surgery, total hip replacement, suprapubic prostatectomy, transurethral resection of the prostate, and upper gastrointestinal endoscopy.

${ }^{7}$ Medicare bite did not affect the acquisition of new technologies and services provided disproportionately to the poor.
} 
managed care plans date back to 1849 , only $5 \%$ of Americans were enrolled in a managed care plan in 1980. By 1995, this number had grown to $73 \%$ (Cutler \& Sheiner, 1998).

In the earlier years, managed care penetration grew slowly because providers and states disapproved of limiting provider networks. Over half of states banned consumer-controlled medical plans, and 17 states required free choice of physician (Gruber et al., 1988). However, after the introduction of Medicare and Medicaid in 1965, federal and state governments gained a vested interest in curbing the rising cost of health care. In 1973, the federal government passed the Health Maintenance Organization Act which encouraged the growth of managed care plans by providing start-up funds to HMOs. Then between 1981 and 1984, several states passed regulations that relaxed their pre-existing constraints against selective contracts between insurers and providers. These policy changes resulted in a rapid escalation of HMO plans (Gabel et al., 1986).

Although the rise in managed care participation began almost exclusively within the private sector, by the late 1980s, it had extended to the public sectors. Medicaid managed care grew after states began contracting with Medicaid managed-care plans, and Medicare managed care expanded through a series of Medicare demonstrations. After verifying the feasibility of capitation payments, Medicare formally established a risk-contracting program for HMOs in 1985. Medicare PPO demonstrations followed suit in the early 1990s (Langwell \& Gordon, 1990).

Like PPS, the effects of managed care on utilization, cost savings, and health quality have been studied extensively. Glied (2000) provides a comprehensive review of the literature, and she notes that estimation is complicated by a few empirical difficulties. First, managed care plans vary in their complexity, and data on factors such as cost-sharing arrangements or the stringency of the utilization review procedures is often not released. Second, there is often selection bias because the individuals who decide to enroll in a managed care plan can be very different in terms of underlying health and health utilization preferences relative to those who choose FFS plans. Results of selection studies suggest that managed care plans enjoy a 20 to $30 \%$ prior utilization advantage by attracting younger families and fewer people who are chronically ill (Berki et al., 1977). Nevertheless, the RAND insurance experiment finds no statistically significant differences between the prior expenditures of those assigned into an HMO and those who voluntarily chose the plan (Manning et al., 1984).

Chernew et al. (1998), Miller \& Luft (1994), and Miller \& Luft (1997) offer detailed reviews of studies that examine the effect of managed care enrollment on utilization. Because of selection bias, they focus on publications that make an attempt to account for differences between managed care and non-managed care enrollees. There is large variation in results, likely stemming from a limited ability to control for selection, imperfect information on plan characteristics, heterogeneity across managed care plans, and non-uniform measures of utilization. Nevertheless, on average, studies conclude that total charges tend to be about 10 to $15 \%$ lower in HMO plans. It is less clear whether PPOs generate the same type of expenditure reductions (Smith, 1997), and it does not appear that Medicaid managed care plans lower Medicaid spending (Duggan \& Hayford, 2013).

While the aforementioned studies identify modest cost savings from managed care plans, it is not equivalent to showing that managed care plans reduce total health care costs. If cost savings are occurring due to the selection of healthier patients or the selective entry of managed care plans into markets that are on average lower cost, then total health costs may actually increase with higher managed care penetration. An extensive review of the studies can be found in Glied (2000) and Baker (2003). Earlier studies, which did not account for potential selection bias, generally find no effect between managed care penetration and total costs. On the other hand, more recent studies, 
which try to limit health plan level selection, find a negative relationship between managed care penetration and the total cost growth rate (e.g., Baker, 1997, Cutler \& Sheiner, 1998, Robinson, 1996).

Others have noted that administrative costs of managed care are particularly high, and the cost of administering utilization controls are higher in the private sector relative to Medicare (Philipson et al., 2010). The lower administrative costs among Medicare are often interpreted as part of the value generated by centralized insurance. To break even with Medicare FFS plans, Brown et al. (1993) estimates that private managed care plans must decrease expenditures by at least $15 \%$ to simply cover administrative costs for marketing, negotiation of provider contracts, and regulatory and compliance management.

There are several channels through which managed care plans can affect health expenditures. Several studies provide evidence that physicians adopt practice styles that apply differently across their insured patients (Baker \& McClellan, 2001, Glied \& Zivin, 2002). Because financial risk has been transferred to providers, they have a greater incentive to reduce the cost of care. Utilization controls, such as having a primary care gatekeeper and pre-authorization requirements, also reduce unnecessary services and improve coordination of care (e.g., Hurley et al., 1991). Miller \& Luft (1994) review the literature and conclude that managed care patients have shorter lengths of stay, fewer inpatient admissions, fewer use of expensive procedures and tests, higher outpatient utilization, and higher use of preventative services.

Other studies focus on the ability of managed care plans to negotiate lower provider prices in the private health insurance market (Cutler et al., 2000). Inefficient providers can be excluded from the network, and patients can be steered to providers who agree to accept discounted payments (Bindman et al., 1998, Mays et al., 2003). The 1990s reduction in Medicare hospital payments further encouraged contracting between insurers and low-cost hospitals.

A final channel through which managed care can reduce costs is by slowing the diffusion of technology. Cutler \& Sheiner (1998) consider several technologies, including advanced cardiac procedures, radiation therapy, diagnostic radiology, and transplant services. They find preliminary evidence that increased HMO enrollment is associated with less-rapid diffusion of new technologies, and this effect increases over time. Baker (2001), Baker \& Wheeler (1998) and Baker \& Phibbs (2001) provide a more detailed study on the impact of HMOs on MRI diffusion and use. They find that high managed care markets have significantly slower diffusion rates of MRIs into hospitals and lower rates of MRI procedure use. Despite the slowdown in technology adoption, quality of care or health outcomes do not appear to be compromised under managed care plans (Ware et al., 1987).

\subsection{Other Factors: Inefficiency and Physician-Induced Demand}

Despite cost containment introduced through the PPS and managed care system, the increasing fragmentation and complexity of payment structures during this time period led to increased administration costs and reduced efficiency. Comparing administrative costs between the US and Canada from 1983 to 1987, Woolhandler \& Himmelstein (1991) show that administrative costs- as a percent of total hospital spending, total costs, or gross income- increased significantly in the US but declined in Canada. These costs can be traced to higher insurance overhead among both private and public insurers, higher hospital and nursing home administration costs, and greater physician overhead and billing expenses. To this day, administrative costs remain one area in which the US 
spends a disproportionately large share of its per capita health expenditures. In 2010, the US spent nearly $\$ 900$ per person per year on administrative costs, whereas Canada spent $\$ 416$ per person per year and Japan spent $\$ 120$ per person per year. 8

In addition to increasing administrative inefficiency, a substantial amount of literature has focused on the idea of physicians encouraging their patients to demand services with minimal benefit (e.g., Evans, 1974, Fuchs, 1978). Known as physician-induced demand, this behavior can occur because patients are not fully informed and physicians act as an agent on behalf of the patient. Researchers have postulated two main theories to explain physician-induced demand (Ellis \& McGuire, 1993, McGuire \& Pauly, 1991). First, physicians might be motivated to maintain a certain level of income, so if their income falls below their target, they will alter their recommendations to produce additional income. Second, as Arrow (1963) first noted, there may be professional uncertainty regarding the effectiveness and success of various treatment options. This uncertainty can create what appears to be physician-induced demand. McGuire (2000) reviews the literature, and concludes that there is a large volume of empirical research that supports the idea of physician-induced demand. However, the literature has not been highly discriminatory between the target income hypothesis and theories with fixed patient preferences. Some of the more compelling evidence for physician-induced demand comes from studying births. For example, Gruber \& Owings (1996) show that obstetricians replace drops in their income due to lower fertility rates by increasing the number of cesarean sections performed.

\section{Period 3: The Managed Care Backlash, 1994-2002}

Transitions into managed care plans were not without controversy. Despite the early enthusiasm for managed care, health care markets underwent an abrupt transition from support for HMOs to retrenchment and disillusionment in the late 1990s. This backlash stemmed from negative consumer sentiments, economic prosperity, legislative responses to consumers, and changes in hospital market power. As health plans lost traction in their efforts to contain costs, premiums increased, returning to the levels of a decade ago. Benefits packages were trimmed, and cost-sharing, particularly for pharmaceuticals, reached new highs.

\subsection{The Response to Managed Care}

Robinson (2001) documents several key developments which led to backlash against managed care. Negative perceptions of managed care began to develop, and these perceptions were influenced by major media attention and several major lawsuits (Blendon et al.,1998). One of the most prominent court cases occurred when a California jury awarded $\$ 89.3$ million to the family of a woman whose Health Net HMO refused to pay for a costly, experimental procedure to treat the breast cancer that ultimately killed her. Another important verdict handed down a \$120 million fine on Aetna US Healthcare for having review processes that delayed a cancer patient's high-dose chemotherapy treatment and bone marrow transplantation.

Public opinion polls showed that consumers, despite having a high personal satisfaction with managed care, held broad negative views of managed care based on anecdotal stories of patients

\footnotetext{
${ }^{8}$ These figures are based on the authors' calculations from the OECD Health Data 2012.
} 
being denied treatment (Brodie et al., 1998, Lesser \& Ginsburg, 2000). Consumers lamented the lower quality of care, poorer access to providers, and administrative hassles that restricted use of care, and internet technology enhanced the ability of consumers to search for and switch among plans (Strunk et al., 2001). With the internet, consumers could easily check eligibility, benefits, and coinsurance limits, and they could read up on others' evaluations of quality.

Employers responded to growing consumer discontent by favoring loosely managed PPOs and open-access HMOs over stricter closed-network plans (Heffler et al., 2001). With the booming mid-1990 to early-2000 economy, employers faced pressure to attract and retain employees, so they catered to their employees' health-insurance preferences. They even absorbed much of the increase in premiums during this period on behalf of their employees. Draper et al. (2002) note that employers saw their premiums increase by $11 \%$ between 2000 and 2001, the highest rate of increase since 1993.

Policymakers responded by adopting regulatory limits on the use of some managed care tools. Between 1999 and 2002, several pieces of managed care consumer legislation passed through the Senate and House, including two Bipartisan Patient Protection Acts (Hearne \& Chaikind (2002)). States themselves enacted dozens of measures, including laws that prohibited primary care gatekeepers, restricted utilization review, and mandated benefits (Cooper III \& Green, 1991). The "any willing provider" laws also ensured that providers had equal access to beneficiaries of managed care plans. Together, these laws made it more difficult for managed care plans to limit coverage or to unreasonably restrict the use of out-of-network providers.

Not all legislation worked against managed care organizations. For example, the Balanced Budget Act of 1997 authorized the HCFA to create Medicare managed care contracts with coordinated plans, such as HMOs and PPOs. At the time, these new health plan contracts were part of the Medicare+Choice program, which, under the Medicare Prescription Drug, Improvement, and Modernization Act of 2003, became known as the Medicare Advantage program. The Balanced Budget Act of 1997 also gave states the authority to mandate enrollment in Medicaid managed care plans without obtaining a federal waiver.

However, these policies were not successful at maintaining enrollment into managed care plans. Gold (2001) notes that the Balanced Budget Act of 1997 occurred during a time when Congress concurrently reduced FFS Medicare prices, translating to lower premiums for Medicare+Choice plans. Furthermore, adequate provider networks became more difficult to form, and the HCFA experienced a complete reorganization of their central office, leading to a diminished ability to approve insurer participation plans. These conditions resulted in plans withdrawing from the Medicare+Choice market or offering less generous benefit designs. Similarly, Medicaid managed care plans became unattractive when Medicaid lowered capitation rates, failed to lessen the burden of providing particularly expensive services, and mandated enrollment (Long \& Yemane, 2005).

Hospitals responded by using their growing market power to negotiate a return to traditional competitive strategies. Throughout the 1990s, the hospital industry was becoming more consolidated through mergers and acquisitions. In 1997, the number of mergers and acquisitions peaked at 310 but fell to 132 in 2000 (Cuellar \& Gertler, 2003). With increased bargaining power, hospitals were able to move toward less restrictive care-management, higher payment rates, and better contract terms. Unlike prior disputes with insurers, the disputes in the early 2000s were notable because provider organizations were willing to walk away from health plan networks, and these disputes involved the largest, most prominent providers in the community (Lesser et al., 2003).

While hospital prices did rise, utilization rates, measured by quantity of services per capita, 
was the largest contributor to the acceleration of hospital spending. Coupled with an increasingly tight labor market, this increase in demand for services led to widely reported shortages of nurses, pharmacology technicians, and imaging and laboratory technicians (Levit et al., 2003). By 2001, the wages for private hospital workers were increasing by $6 \%$ a year.

Finally, insurers responded to provider, consumer, and governmental pressures by offering fewer managed care plans, outrunning costs by raising premiums, and increasing cost-sharing (Robinson, 2001). This response corresponds to the observation that between 1994 to 2001, the growth rate of private expenditures and out-of-pocket costs both increased by 5 percentage points.

\subsection{Other Factors: Medicaid Expansions, Medicare Legislation, and Pre- scription Drugs}

Other factors contributed to the rise in health expenditures during this period: extended Medicaid eligibility, higher Medicare payouts, and a growth in prescription drug spending. Between 1994 and 1996, Medicaid coverage declined due to strong economic growth and the disentanglement between Medicaid eligibility and eligibility for Temporary Assistance for Needy Families. However in 1997, Medicaid coverage expanded significantly with the State Children's Health Insurance Program (SCHIP). Established through the Balanced Budget Act of 1997, SCHIP allocated \$40 billion over 10 years to aid states in expanding their Medicaid programs to low-income children. By 1999, SCHIP enrollment had already reached 1.8 million, and this figure continued to rise to 3.9 million in 2003. The increased enrollment into SCHIP led to not only an increase in state and federal health expenditures, but also a rise in utilization rates among the newly insured.

Medicare payment policies also contributed to the expenditure growth. Although the Balanced Budget Act of 1997 made several large financial cuts with the hopes of reducing spending, the Clinton administration, amidst growing political pressure, passed the Medicare, Medicaid, and SCHIP Balanced Budget Refinement Act of 1999. This 1999 act restored \$27 billion to various providers, with the biggest winners being Medicare managed care organizations. It also canceled the proposed across-the-board reductions to the outpatient PPS and protected providers against any losses incurred during the first three years of outpatient-PPS implementation.

Finally, towards the end of the 1990s, spending on prescription drugs began to grow. Insurers increasingly adopted three-tier pharmacy benefits that required consumers to pay higher co-pays for preferred and brand-name drugs (Mays et al., 2003). Patients also began using drug therapies for longer periods of time. Drug companies invested in more more direct-to-consumer advertising, and they received extended patent lives. Whereas the effective patent life averaged 8.1 years between 1980 and 1984, the "base" patent life in the late 1990s had been increased to 9.5 years, with possible extensions of up to 15.4 years (Heffler et al., 2001). However, these patterns eventually shifted.

\section{Period 4: The Golden Era, 2002-2015}

In 2002, the growth rate of health expenditures fell again, but unlike the fits and starts from the policy era, this slowdown has been sustained and continuous. From 2009 to 2013, the annual health expenditure growth rate has not exceeded $4 \%$, a phenomenon not experienced since the $1960 \mathrm{~s}$. We 
know surprisingly little about the root causes. Many have focused on identifying whether this slowdown in health spending is a result of (1) broader economic factors, (2) structural changes in the health care system, or (3) both. If broader economic factors are driving the observed slowdown, one can expect that the growth rate of health expenditures to rise in the future. However if structural changes are more responsible, then one can expect a continuation of historically low growth rates.

\subsection{The Role of the Economy}

One obvious culprit is the great recession, and several studies have considered the role of economic downturns in explaining the slowdown in growth. The results point to an economic contribution, but there is no consensus on the magnitude. Levitt et al. (2013) use a time series analysis to identify macroeconomic variables that are highly predictive of the growth in health spending in any given year. By focusing on inflation and growth in real GDP, they conclude that macroeconomic effects account for $77 \%$ of the recent decline in health spending growth. Instead of assuming a constant relationship between GDP and spending across all years, Dranove et al. (2014) exploits variation in the regional severity of the economic slowdown to similarly conclude that the recession explains approximately $70 \%$ of the slowdown from 2007 to 2011 . Others have attributed a much smaller role to the recession. Cutler \& Sahni (2013) form projections for expected health spending based on economic models, and they conclude that the recession accounted for $37 \%$ of the overall slowdown in expenditures from 2003 to 2012. Levine \& Buntin (2013) find no evidence that unemployment, loss income, or declines in the values of beneficiaries' assets affects use of services among Medicare beneficiaries.

Of these studies, few focus on identifying the mechanisms by which recessions affect health spending. Demand is likely a factor. Recessions can lower consumer income, reduce the availability of employer-sponsored insurance through job loss, or cause employers to reduce health benefits on existing plans. All of these channels will reduce utilization of health services. Ryu et al. (2013) use data on the health spending behavior of beneficiaries at large firms to parse apart these effects. They show that the effects of the recession extend beyond job loss, and the reductions in health spending occurred primarily because of rising out of pocket costs. An alternative effect of the recession is to shift private coverage towards public coverage. Holahan \& McMorrow (2013), Truffer et al. (2010) and Sisko et al. (2009) note that between 2007 and 2012, both Medicaid enrollment and spending increased. However, the growth in Medicaid spending per enrollee has been well below the growth rate in the medical care consumer price index, suggesting that Medicaid has been able to keep cost increases below that of other sectors in the health system (Young et al. 2014).

However, the recession does not tell the whole story. Figure 3 shows that the slowdown in expenditures clearly extends beyond the recession periods. The slowdown began as we exited the 2001 recession, and it has continued through 2013. While the decrease in health expenditure growth appears particularly pronounced during the Great Recession from 2007 to 2009, other factors must be responsible for at least the pre-recession decline.

\subsection{Demand-Side Structural Changes}

Some have pointed to permanent changes in benefit design, beyond the effects of the recession, to explain why the slowdown is permanent (e,g., Cutler \& Sahni, 2013). Although the growth rate of beneficiary out-of-pocket costs remained constant between 2002-2006 and 2007-2011, Baicker 
\& Goldman (2011) note that the level of real per capita out-of-pocket spending has been increasing. The prevalence of managed care plans has also increased. By 2010, only $1 \%$ of employersponsored plans were FFS plans. Health economists since Arrow have worked on optimal insurance design, and the increase in patient cost-sharing can be seen as a move to more efficient designs. However, few plans implement cost-sharing that discriminate between the use of highversus low-value care. Through various insurance structures, patients can be incentivized to utilize care more efficiently. One such structure is value-based insurance design (VBID) plans which align patients' out-of-pocket costs with the value of the health services they receive. For example, statin co-payments may be lowered for patients with coronary artery disease but not for those receiving treatment for primary prevention. While the literature suggests that modest benefits are realized through VBID, it is unclear whether these programs are cost-saving. Lee et al. (2013) review thirteen studies and conclude that VBID designs improve adherence and lower out-of-pocket spending for drugs. They do not find any significant changes in overall medical spending. However, Goldman et al. (2007) and Mahoney (2008), two studies not reviewed by Lee et al. (2013), find decreases in total health costs. In addition to inconclusive evidence on health costs, little work has been done to estimate the administrative costs of implementing VBID programs. Establishing VBID programs can require considerable effort because the value of a given service changes across subgroups of patients. VBID programs have contributed to the slowdown in health spending only to the extent that they help reduce total expenditures.

Consumer directed health plans (CDHPs), introduced in the mid 2000s, may also have contributed to the slowdown in health expenditures. These plans combine high deductible coverage with tax-exempt savings accounts, which are used to pay for routine health care expense. The goal of these savings accounts was to encourage consumers to be more cost-conscious users of health care. CDHPs started to rise in popularity when regulation passed by the Internal Revenue Service between 2001 and 2002 aided in the establishment of health retirement accounts. Health retirement accounts are a type of CDHP where an employer adds funds for an employee's health expenses. Unused funds revert to the employer if the employee leaves the company. An alternative plan that allowed for greater consumer involvement- health savings accounts- was established in the 2003 Medicare Modernization Act. In a health savings account, both the employer and employee can contribute to the account, but the funds are portable with the employee.

There is robust empirical evidence that CDHPs effectively incentivize patients to change their health care use and reduce costs in the first year after introduction (e.g., Buntin et al., 2011, Lo Sasso et al. 2010). Researchers have also established longer term impacts of an approximately $15 \%$ reduction in total spending within the first three years of CDHP enrollment (Haviland et al., 2015). Wilensky (2006) suggests that in addition to lower costs, hospitals might be pressured to increase price transparency and establish greater uniformity in pricing. Nevertheless, reductions in use may not lead to better health outcomes. Several studies have found that higher drug cost sharing can reduce the use of essential chronic-illness medications. For example, Gaynor et al. (2006) find that consumers substitute prescription drug use with outpatient care, and $35 \%$ of savings achieved by reductions in drug spending are offset by consequent increases in other medical spending. Goldman et al. (2007) find that increased cost sharing is associated with lower rates of drug treatment, worse adherence, and more frequent discontinuation of therapy.

Finally, the 2006 passage of Medicare Part D, the Medicare prescription drug plan, certainly increased demand for pharmaceuticals, but there is also evidence it may have reduced total spending. Part D spending depends on several factors, including the number of Part D enrollees, their 
health status, and their drug use. It also depends on each plan's ability to manage use and negotiate discounts. Actual Part D spending has been lower than anticipated because enrollment has been lower than projected. Furthermore, Part D plan sponsors have been able to negotiate on average $15 \%$ savings relative to retail prices, and the majority of beneficiary spending on brand-name drugs has occurred within preferred tiers of Part D plans (CBO, 2014). Shang \& Goldman (2010) further show that a $\$ 1$ increase in prescription drug spending is associated with a $\$ 2.06$ reduction in Medicare spending because prescription drugs and medical services covered by Medicare Parts A and $\mathrm{B}$ are substitutes.

\subsection{Supply-Side Structural Changes}

Others attribute the slowdown to changes in the organization and delivery care, with the rise of Accountable Care Organizations (ACOs) being perhaps the most popular. First coined in around 2006, ACOs are groups of doctors, hospitals, and other providers who come together to voluntarily coordinate care. The popularity of ACOs has grown over time with an estimated $14 \%$ of the US population now being served by an ACO (Gold, 2014). The research on these organizations remains limited, but initial work suggests that some ACOs share in savings of up to $\$ 300$ million while other ACOs have insignificant impacts on spending relative to their benchmarks (McClellan et al., 2015). Regardless of the potential cost-containment benefits, ACOs grew in popularity grew mainly after the Patient Protection and Affordable Care Act (ACA), and they cannot explain the earlier slowdown in health expenditures observed from 2000 to 2006.

Another supply-side change is a growing emphasis on preventive care. Thorpe (2005) notes that changes in clinical thresholds for treatment have resulted in earlier interventions. For example, the thresholds for hypertension have been steadily lowered from 160/95 mmHG in 1980 to 140/90 mmHg. The lowered threshold expands the number of Americans targeted for primary prevention. 9 Similar changes have occurred with lipid controls for cholesterol and glucose levels for diabetes. Although several components of the ACA emphasize the importance of preventive care, the evidence on the cost-saving potential of preventive care remains mixed. Cohen et al. (2008) review 599 studies in the literature. They conclude that focusing on certain preventable causes of death, such as poor diet, physical inactivity, and smoking, can generate cost savings, but not all preventive measures represent cost-effective care.

Other studies have focused on the decline of health care prices over time. While isolating the price component of changes in health expenditures may be difficult, White \& Ginsburg (2012) note that the trend toward tighter Medicare payment policies began in the middle of the 2000s. The Deficit Reduction Act of 2005 reduced payment rates for imaging, home health services, and durable medical equipment while the Medicare Improvements for Patients and Providers Act of 2008 made substantial cuts to Medicare Advantage plans. More generally, Medicare payments have risen below the relevant index of inflation each year (Martin et al., 2014). Since private payments tend to follow changes in Medicare fees, it is possible that tighter Medicare payment policies created spillover effects in private payments as well (Clemens \& Gottlieb, 2013).

Finally, some researchers cite the slowdown in technology and pharmaceutical development as a potential explanation for the slowing spending growth. Cutler \& Sahni (2013) note that spending on prescription drugs has fallen from a $10.1 \%$ annual growth rate between 1993 to 2003 to a $2.3 \%$

\footnotetext{
${ }^{9}$ The first number represents the systolic blood pressure; the second represents the diastolic blood pressure.
} 
annual growth rate between 2003 and 2012. They attribute this decline to the the number of drugs coming off patent and fewer introductions of new blockbusters. Furthermore, drugs that accounted for roughly $17 \%$ of prescription drug spending in 2013 are coming off patent in the next five years. Similar patterns have been observed for the use of expensive imaging technology. While the use of advanced imaging use previously grew at an annual rate of $6 \%$ or more, the use of imaging decelerated around 2005 (Lee \& Levy, 2012).

\subsection{Demographic Shifts}

Although economic and structural factors may have lowered costs, many demographic factorsincluding a growing aging population and the rising prevalence of chronic diseases, notably obesity, across all age cohorts- have contributed to increasing health expenditures. Relative to those ages 35 to 44, the average per capita health spending for Americans in 1999 ages 75 and older was five times as high. Many have concluded that the increasing fraction of elderly in the overall population will contribute to increasing health expenditures (Schneider \& Guralnik, 1990). Nevertheless, Reinhardt (2003) notes that the annual growth in spending has affected per capita spending for all age groups, and the aging population is too gradual a process to rank as a major cost drive in health care.

Another key demographic factor is that the US population has become less healthy over time. Beginning in the 1980s, the obesity rate shot up, increasing from $15 \%$ of the adult population to $35 \%$ of the population by the mid-2000s. Thorpe et al. (2004) find that obesity is responsible for $25 \%$ of the rise in health spending from 1987 to 2001, and Finkelstein et al. (2009) conclude that the annual medical burden of obesity has increased to almost $10 \%$ of all medical spending between 1998 and 2006. While the prevalence of obesity has remained fairly stable from 2003 through 2010, more recent CDC data suggests that there have been statistically significant decreases in obesity prevalence among children ages 2 to 5 and women 60 and older (Ogden et al., 2014).

More generally, the number and proportion of Americans living with chronic diseases, including heart disease, asthma, cancer, and diabetes, have been increasing over time (Hoffman et al. 1996). Lakdawalla et al. (2004) further highlight that disability rates among people under age 50 have been increasing, in part because general health among the young has been deteriorating. Treatment for people with chronic diseases and conditions account for most of health care costs. According to the Centers for Disease Control and Prevention, the treatment of those with chronic diseases and conditions accounts for $86 \%$ of all health care spending in 2010 . They also estimated that heart disease and strokes together cost at least $\$ 315$ billion, cancer care cost $\$ 157$ billion, diabetes cost $\$ 245$ billion, arthritis and related conditions cost $\$ 128$ billion, and medical costs linked to obesity cost $\$ 147$ billion.

\section{Conclusion}

Since the 1950s, life expectancy in the US has risen at a steady pace, driven mostly by reduced mortality at older ages. The social benefits of these improvements are tremendous- on the order of $50 \%$ of US gross domestic product- although these gains are not widely recognized (Murphy

\& Topel, 2016). These improvements have also come at substantial cost, with the US devoting an 
increasing share of its income to health care. Health economists have demonstrated that health care is a normal good, so it is not surprising that the US is not unique. Figure 4 shows the excess health spending growth between the US and other OECD countries over time. Following Squires (2014), we define excess health spending growth as the percent change in annual health expenditures that exceeds the percent change in the annual GDP, and we compare the US to a population-weighted average of 12 OECD countries. As Figure 4 demonstrates, changes in the excess health-spending growth rate have been quite similar between the US and other countries.

Clearly there are universal factors at play, and health economists have also demonstrated that technology plays a crucial role. However, it is also the case that technology is treated as a âĂIJresidualâĂİ for the unexplained portion of spending growth. Chandra \& Skinner (2012) categorize technological progress in health care based on its impact on cost and health: (1) highefficiency, low-cost innovations; (2) costly innovations with high efficiency for particular subgroups; and (3) costly innovations with uncertain efficiency. The first two lead to large improvements in life expectancy, but they are not to be blamed for the rise in health spending relative to other nations. It is the third category that has been uniquely abundant in the US.

The field of health economics has been most successful in identifying payment system reforms and demand-side controls that can slow the diffusion of these innovations, without an immediate hit to population health, at least in the short-run. Longer term, there is question of whether efforts to control technology will induce a harmful reduction in innovation, with personalized medicinecurrently showing great promise but also great expense- being a notable example. We clearly need a better understanding of what precisely constitutes innovation, how it diffuses, and whether it can be harnessed to slow spending growth in a way that is socially desirable. Given the successes of the past half century, this seems well within the realm of possibility. 


\section{References}

Arrow K. 1963. Uncertainty and the welfare economics of medical care. The American Economic Review 53:941-973

Asgeirsdottir TL, Corman H, Noonan K, Olafsdottir P, Reichman NE. 2014. Was the economic crisis of 2008 good for icelanders? impact on health behaviors. Economics and Human Biology 13:1-19

Baicker K, Chandra A. 2004. Medicare spending, the physician workforce, and beneficiaries' quality of care. Health Affairs w4:184-197

Baicker K, Goldman D. 2011. Patient cost-sharing and health spending growth. Journal of Economic Perspectives 25:47-68

Baker L. 1997. The effect of hmos on fee-for-service health care expenditures: Evidence from medicare. Journal of Health Economics 16:453-481

Baker L. 2001. Managed care and technology adoption in health care: Evidence from magnetic resonance imaging. Journal of Health Economics 20:395-421

Baker L. 2003. Managed care spillover effects. Annual Review of Public Health 24:435-456

Baker L, McClellan M. 2001. Managed care, health care quality, and regulation. The Journal of Legal Studies 30:715-741

Baker L, Phibbs C. 2001. Managed care and technology adoption in health care: Evidence from magnetic resonance imaging. Journal of Health Economics 20:395-421

Baker L, Wheeler S. 1998. Managed care and technology diffusion: The case of mri. Health Affairs 17:195-207

Berki S, Ashcraft M, Penchansky R, Fortus R. 1977. Enrollment choice in a multi-hmo setting: The roles of health risk, financial vulnerability, and access to care. Medical Care 15:95-114

Bindman A, Grumbach K, Vranizan K, Jaffe D, Osmond D. 1998. Selection and exclusion of primary care physician by managed care organizations. The Journal of American Medical Association 279:675-679

Blendon R, Brodie M, Benson J, Altman D, Levitt L, et al. 1998. Understanding the managed care backlash. Health Affairs 17:80-94

Brodie M, Brady LA, Altman D. 1998. Media coverage of managed care: Is there a negative bias? Health Affairs 34:9-25

Brook R, Chassin M, Fink A, Solomon D, Kosecoff J, Park R. 1986. A method for the detailed assessment of the appropriateness of medical technologies. International Journal of Technology Assessment in Health Care 4:53-63 
Brown R, Bergeron J, Clement DG, Hill J, Retchin S. 1993. Does managed care work for medicare? an evaluation of the medicare risk program for hmos. Princeton, NJ: Mathematica Policy Research, Inc

Buntin M, Haviland A, McDevitt R, Sood N. 2011. Health care spending and preventive care in high-deductible and consumer-directed health plans. American Journal of Managed Care 17:222-230

Card D, Dobkin C, Maestas N. 2008. The impact of nearly universal insurance coverage on health care utilization: Evidence from medicare. American Economic Review 98:2242-2258

Carter G, Newhouse J, Rellas D. 1990. How much change in the case mix index is drg creep? RAND Publication Series

Catalano R, Goldman-Mellor S, Saxton K, Margerison-Zilko C, Subbaraman M, et al. 2011. The health effects of economic decline. Annual Review of Public Health 32:1-25

Catlin A, Cowan C, Hartman M, Heffler S, the National Health Expenditure Accounts Team. 2008. National health spending in 2006: A year of change for prescription drugs. Health Affairs 27:116

Chandra A, Skinner J. 2012. Technology growth and expenditure growth in health care. Journal of Economic Literature 50:645-680

Charles KK, DeCicca P. 2008. Local labor market fluctuations and health: Is there a connection and for whom? Journal of Health Economics 27:1532-1550

Chernew M, Hirth R, Cutler D. 2009. Increased spending on health care: Long-term implications for the nation. Health Affairs 28:1253-1255

Chernew M, Hirth R, Sonnad S, Ermann R, Fendrick AM. 1998. Managed care, medical technology, and health care cost growth: A review of the evidence. Medical Care Research and Review 55:259-288

Clemens J, Gottlieb J. 2013. In the shadow of a giant: Medicare's influence on private physician payments. NBER Working Paper

Cohen J, Neumann P, Weinstein M. 2008. Does preventive care save money? health economics and the presidential candidates. The New England Journal of Medicine 358:661-663

Congressional Budget Office. 2014. An update to the budget and economic outlook: 2014-2024

Cooper III P, Green K. 1991. The impact of state laws on managed care. Health Affaris 10:161-169

Coulam RF, Gaumer GL. 1992. Medicare's prospective payment system: A critical appraisal. Health Care Financing Review 1991:45-77

Cromwell J, Mitchell J. 1986. Physician-induced demand for surgery. Journal of Health Economics 5:293-313 
Cromwell J, Pope GC. 1989. Trends in hospital labor and total factor productivity, 1981-86. Health Care Financing Review 10:39-50

Cuellar AE, Gertler P. 2003. Trends in hospital consolidation: The formation of local systems. Health Affairs 22:77-87

Cutler D. 1998. Cost shifting or cost cutting? the incidence of reductions in medicare payments. In Tax Policy and the Economy, ed. J Poterba, vol. 12. MIT Press, 1-28

Cutler D, Lleras-Muney A. 2008. Making americans healthier, chap. Education and Health: Evaluating Theories and Evidence. Russell Sage Foundation, 29-60

Cutler D, McClellan M. 2001. Is technological change in medicine worth it? Health Affairs 20:1129

Cutler D, McClellan M, Newhouse J. 2000. How does managed care do it? RAND Journal of Economics 31:526-548

Cutler D, Rosen AB, Vijan S. 2006. The value of medical spending in the united states, 1960-2000. The New England Journal of Medicine 355:920-927

Cutler D, Sahni N. 2013. If slow rate of health care spending growth persists, projections may be off by $\$ 770$ billion. Health Affairs 32:841-850

Cutler D, Sheiner L. 1998. Managed care and the growth of medical expenditures. In Frontiers in Health Policy Research, ed. A Garber. MIT, 77-116

Dafny LS. 2005. How do hospitals respond to price changes? The American Economic Review 95:1525-1547

Dehejia R, Lleras-Muney A. 2004. Booms, busts, and babies' health. Quarterly Journal of Economics 119:1091-1130

DesHarnais S, Chesney J, Fleming S. 1988. Trends and regional variations in hospital utilization and quality during the first two years of the prospective payment system. Inquiry 25:374-382

Dranove D, Garthwaite C, Ody C. 2014. Health spending slowdown is mostly due to economic factors, not structural change in the health care sector. Health Affairs 33:1399-1406

Draper D, Hurley R, Lesser C, Strunk B. 2002. The changing face of managed care. Health Affaris $21: 11-23$

Duggan M, Hayford T. 2013. Has the shift to managed care reduced medicaid expenditures? evidence from state and local-level mandates. Journal of Policy Analysis and Management 32:505535

Ellis R, McGuire T. 1993. Supply-side and demand-side cost sharing in health care. Journal of Economic Perspectives 7:135-151 
Evans R. 1974. Supplier-induced demand: Some empirical evidence and implications. Macmillan, $162-173$

Feder J, Hadley J, Zuckerman S. 1987. How did medicare's prospective payment system affect hospitals? New England Journal of Medicine 317:867-873

Feldstein M, Friedman B. 1977. Tax subsidies, the rational demand for insurance, and the health care crisis. Journal of Public Economics 72:155-178

Finkelstein A. 2007. The aggregate effects of health insurance: Evidence from the introduction of medicare. The Quarterly Journal of Economics 122:1-37

Finkelstein A, Gentzkow M, Williams H. 2014. Sources of geographic variation in health care: Evidence from patient migration. NBER Working Paper 20789

Finkelstein A, Taubman S, Wright B, Bernstein M, Gruber J, et al. 2012. The oregon health insurance experiment: Evidence from the first year. Quarterly Journal of Economics 127:1057-1106

Finkelstein E, Trogdon J, Cohen J, Dietz W. 2009. Annual medical spending attributable to obesity: Payer-and service-specific estimates. Health Affairs 28:w822-w831

Fisher ES, Wennberg DE, Stukel TA, Gottlieb DJ, Lucas F, Pinder EL. 2003a. The implications of regional variations in medicare spending. part 1: The content, quality, and accessibility of care. Annals of Internal Medicine 138:273-287

Fisher ES, Wennberg DE, Stukel TA, Gottlieb DJ, Lucas F, Pinder EL. 2003b. The implications of regional variations in medicare spending. part 2: Health outcomes and satisfaction with care. Annals of Internal Medicine 138:288-298

Fuchs VR. 1978. The supply of surgeons and the demand for operations. The Journal of Human Resources 13:35-56

Gabel J, Ermann D, Rice T, de Lissovoy G. 1986. The emergence and future of ppos. Journal of Health Politics, Policy and Law 11:305-322

Gaynor M, Li J, Vogt W. 2006. Is drug coverage a free lunch? cross-price elasticities and the design of prescription drug benefits. NBER Working Paper

Giacalone JA. 2001. The us nursing home industry. M. E. Sharpe, Inc

Gibson RM, Levit KR, Laznby H, Waldo DR. 1984. National health expenditures, 1983. Health Care Financing Review 6:1-29

Ginsburg P, Carter G. 1986. Medicare case-mix index increase. Health Care Financing Review $7: 51-65$

Glied S. 2000. Handbook of health economics, chap. 13: Managed Care. Elsevier, 707-753

Glied S, Zivin JG. 2002. How do doctors behave when some (but not all) of their patients are in managed care? Journal of Health Economics 21:337-353 
Gold J. 2014. Faq on acos: Accountable care organizations, explained. Kaiser Health News

Gold M. 2001. Medicare + choice: An interim report card. Health Affairs 20:120-138

Goldman D, Joyce G, Zheng Y. 2007. Prescription drug cost sharing associations with medication and medical utilization and spending and health. The Journal of the American Medical Association 298:61-69

Grossman M. 2000. Handbook of health economics, vol. 1, chap. The Human Capital Model. Elsevier, 347-408

Gruber J, Owings M. 1996. Physician financial incentives and cesarean section delivery. The RAND Journal of Economics 27:99-123

Gruber L, SHadle M, Polich C. 1988. From movement to industry: The growth of hmos. Health Affairs 7:197-208

Hadley J, Zuckerman S. 1990. Changes in hospitals' charges to privately insured patients during pps. Project Report 3429-07. Washington, D.C.: The Urban Institute

Hadley J, Zuckerman S, Feder J. 1989. Profits and fiscal pressure in the prospective payment system: Their impacts on hospitals. Inquiry 26:354-365

Hall R, Jones C. 2007. The value of life and the rise in health spending. Quarterly Journal of Economics 122:39-72

Haviland A, Eisenberg M, Mehrotra A, Huckfeldt P, Sood N. 2015. Do "consumer-directed" health plans bend the cost curve over time? NBER Working Paper

Hearne J, Chaikind HR. 2002. Patient protection and managed care: Legislation in the 107th congress. Congressional Research Service Issue Brieffor Congress IB98017:1-15

Heffler S, Levit K, Smith S, Smith C, Cowan C, et al. 2001. Health spending growth up in 1999; faster growth expected in the future. Health Affairs 20:193-203

Hoffman C, Rice D, Sung HY. 1996. Persons with chronic conditions: Their prevalence and costs. The Journal of the American Medical Association 276:1473-1479

Holahan J, McMorrow S. 2013. What drove the recent slowdown in health spending growth and can it continue? The Urban Institute Research Report :1-10

Holmstrom B. 1979. Moral hazard and observability. The Bell Journal of Economics 10:74-91

Hurley R, Freund D, Gage B. 1991. Gatekeeper effects on patterns of physician use. Journal of Family Practice 32:167-174

Kahn KL, Keeler EB, Sherwood MJ, Rogers WH, Draper D, et al. 1990. Comparing outcomes of care before and after implementation of the drg-based prospective payment system. The Journal of American Medical Association 264:1984-1988 
Kolstad J, Kowalski A. 2012. The impact of health care reform on hospital and preventative care: Evidence from massachusetts. Journal of Public Economics 96:909-929

Lakdawalla D, Bhattacharya J, Goldman D. 2004. Are the young becoming more disabled? Health Affairs 23:168-176

Langwell K, Gordon N. 1990. Managed care and the medicare program: Background and evidence. Washington, D.C.: Congressional Budget Office

Lee D, Levy F. 2012. The sharp slowdown in growth of medical imaging: An early analysis suggests combination of policies was the cause. Health Affaris 31:w1-w9

Lee J, Maciejewski M, Raju S, Shrank W, Choudhry N. 2013. Value-based insurance design: Quality improvement but no cost savings. Health Affairs 32:1251-1257

Lesser C, Ginsburg P. 2000. Update on the nation's health care system: 1997-1999. Health Affairs 19:206-216

Lesser C, Ginsburg P, Devers K. 2003. The end of an era: What became of the "manged care revolution" in 2001? Health Services Research 38:337-355

Levine M, Buntin M. 2013. Why has growth in spending for fee-for-service medicare slowed? Congressional Budget Office Working Paper Series

Levit K, Smith C, Cowan C, Lazenby H, Sensenig A, Catlin A. 2003. Trends in u.s. health care spending, 2001. Health Affairs 22:154-164

Levitt L, Claxton G, Roehrig C, Getzen T. 2013. Assessing the effects of the economy on the recent slowdown in health spending. The Kaiser Family Foundation Report

Liu S, Chollet D. 2006. Price and income elasticity of the demand for health insurance and health care services. Mathematica Policy Research Reports

Lo Sasso A, Helmchen L, Kaestner R. 2010. The effects of consumer-directed health plans on health care spending. The Journal of Risk and Insurance 77:85-103

Lohr KN. 1990. Medicare: A strategy for quality assurance, volume ii: Sources and methods. National Academy of Science

Long MJ, Chesney JD, Ament RP, DesHarnais SI, Fleming ST, et al. 1987. The effect of pps on hospital product and productivity. Medical Care 25:528-538

Long S, Yemane A. 2005. Commercial plans in medicaid managed care: Understanding who stays and who leaves. Health Affairs 24:1084-1094

Mahoney J. 2008. Value-based benefit design: Using a predictive modeling approach to improve compliance. Journal of Managed Care Pharmacy 14:3-8

Manning W, Leibowitz A, Goldberg G, Rogers W, Newhouse J. 1984. A controlled trial of the effect of a prepaid group practice on use of services. New England Journal of Medicine 310:15051510 
Manning W, Newhouse J, Duan N, Keeler E, Benjamin B, et al. 1988. Health insurance and the demand for medical care: Evidence from a randomized experiment. The RAND Corporation

Manning W, Newhouse JP, Duan N, Keeler EB, Leibowitz A. 1987. Health insurance and the demand for medical care: Evidence from a randomized experiment. American Economic Review 77:251-277

Martin A, Hartman M, Whittle L, Catlin A, the National Health Expenditure Accounts Team. 2014. National health spending in 2012: Rate of health spending growth remained low for the fourth consecutive year. Health Affairs 33:66-77

Mays G, Hurley R, Grossman J. 2003. An empty toolbox? changes in health plans' approaches for managing costs and care. Health Services Research 38:375-393

McClellan M, Kocot SL, White R. 2015. Early evidence on medicare acos and next steps for the medicare aco program (updated). Health Affairs Blog

McGuire T. 2000. Physician agency. Handbook of Health Economics 1:461-536

McGuire TG, Pauly MV. 1991. Physician response to fee changes with multiple payers. Journal of Health Economics 10:385-410

Miller R, Luft H. 1994. Managed care plan performance since 1980. The Journal of American Medical Association 271:1512-1519

Miller R, Luft H. 1997. Does managed care lead to better or worse quality of care? Health Affairs $16: 7-25$

Morris JD. 1954. Eisenhower wins income tax fight in house, 210 to 204: Aid on dividends but rise in exemptions fails as the omnibus reform bill passes. The New York Times

Moseley JB, O’Malley K, Petersen N, Menke T, Brody B, et al. 2002. A controlled trial of arthroscopic surgery for osteoarthritis of the knee. The New England Journal of Medicine 347:81-88

Murphy K, Topel R. 2016. The value of health and longevity. Journal of Political Economy 114:871-904

Newhouse J. 1977. Medical-care expenditure: A cross-national survey. The Journal of Human Resources 12:115-125

Newhouse J. 1992. Medical care costs: How much welfare loss? Journal of Economic Perspectives $6: 3-21$

Ogden C, Carroll M, Kit B, Flegal K. 2014. Prevalence of childhoood and adult obesity in the united states, 2011-2012. The Journal of the American Medical Association 311:806-814

Pauly M. 1968. The economics of moral hazard: Comment. The American Economic Review 58:531-537 
Pauly M. 1974. Overinsurance and public provision of insurance: The roles of moral hazard and adverse selection. Quarterly Journal of Economics 88:44-62

Phelps CE, Mooney C. 1993. Competitive approaches to health care reform, chap. Variations in Medical Practice Use: Causes and Consequences. Urban Institute, 140-78

Philipson T, Seabury S, Lockwood L, Goldman D, Lakdawalla D. 2010. Geographic variation in heatlh care: The role of private markets. Brookings Papers on Economic Activity:325-361

Rae M, Claxton G, Panchal N, Levitt L. 2014. Tax subsidies for private health insurance. Kaiser Family Foundation Issue Brief :1-20

Reed LS. 1947. Blue cross and medical service plans. Washington: Federal Security Agency, U.S. Public Health Service

Reeder CE, Nelson AA. 1985. The differential impact of copayment on drug use in a medicaid population. Inquiry 22:396-403

Reinhardt U. 2003. Does the aging of the population really drive the demand for health care? Health Affairs 22:27-39

Rice TH. 1983. The impact of changing medicare reimbursement rates on physician-induced demand. Medical Care 21:803-815

Ringel J, Hosek S, Vollaard B, Mahnovski S. 2002. The elasticity of demand for health care: A review of the literature and its application to the military health system. RAND Health

Robinson J. 2001. The end of managed care. The Journal of the American Medical Association 285:2622-2628

Robinson JC. 1996. Decline in hospital utilization and cost inflation under managed care in california. The Journal of American Medical Association 276:1060-1064

Ruhm C. 2000. Are recessions good for your health? Quarterly Journal of Economics 115:617650

Ruhm C, Black W. 2002. Does drinking really decrease in bad times? Journal of Health Economics 21:659-678

Ryu A, Gibson T, McKellar R, Chernew M. 2013. The slowdown in health care spending in 200911 reflected factors other than the weak economy and thus may persist. Health Affairs 32:835840

Sanger-Katz M, Quealy K. 2014. Medicare: Not such a budget-buster anymore. New York Times Aug 27

Schneider E, Guralnik J. 1990. The aging of america: Impact on health care costs. The Journal of the American Medical Association 263:2335-2340 
Shang B, Goldman D. 2010. Prescription drug coverage and medicare spending among us elderly. The Geneva Papers on Risk and Insurance: Issues and Practice

Sisko A, Truffe C, Smith S, Keehan S, Cylus J, et al. 2009. Health spending projections through 2018: Recession effects add uncertainty to the outlook. Health Affairs 28:w346-57

Sloan F, Morrisey M, Joseph V. 1988. Medicare prospective payment and the use of medical technologies in hospitals. Medical Care 26:837-853

Smith D. 1997. The effects of preferred provider organizations on health care use and costs. Inquiry 34:278-287

Spillman B, Lubitz J. 2000. The effect of longevity on spending for acute and long-term care. The New England Journal of Medicine 342:1409-1415

Squires D. 2014. The global slowdown in health care spending growth. The Journal of the American Medical Association 312:485-486

Strunk B, Devers K, Hurley R. 2001. Health plan-provider showdowns on the rise. Community Tracking Study Issue Brief No. 40

Stuart B, Zacker C. 1999. Who bears the burden of medicaid drug copayment policies? Health Affairs 18:201-212

Temel J, Greer J, Muzikansky A, Gallgher E, Admane S, et al. 2010. Early palliative care for patients with metastatic non-small-cell lung cancer. The New England Journal of Medicine 363:733-742

Thomasson M. 2004. Early evidence of an adverse selection death spiral? the case of blue cross and blue shield. Exploration in Economic History 41:313-328

Thorpe K. 2005. The rise in health care spending and what to do about it? Health Affairs 24:14361445

Thorpe K, Florence C, Howard D, Joski P. 2004. Trends: The impact of obesity on rising medical spending. Health Affairs w4:480-486

Truffer C, Keehan S, Smith S, Cylus J, Sisko A, et al. 2010. Health spending projections through 2019: The recession's impact continues. Health Affairs 29:522-529

Ware J, Brook R, Keeler WRE, Davies AR, Sherbounre C, et al. 1987. Health outcomes for adults in prepaid and fee-for-service systems of care: Results from the health insurance experiment. Tech. Rep. R-3459-HHS, RAND

Weisbrod B. 1991. The health care quadrilemma: An essay on technological change, insurance, quality of care, and cost containment. Journal of Economic Literature 29:523-552

White C, Ginsburg P. 2012. Slower growth in medicare spending- is this the new normal? The New England Journal of Medicine 366:1073-1075 
Wilensky G. 2006. Consumer-driven health plans: Early evidence and potential impact on hospitals. Health Affairs 25:174-185

Woolhandler S, Himmelstein D. 1991. The deteriorating administrative efficiency of the health care system. The New England Journal of Medicine 324:1253-1258

Young K, Clemans-Cope L, Lawton E, Holahan J. 2014. Medicaid spending growth in the great recession and its aftermath, fy 2007-2012. The Kaiser Commission on Medicaid and the Uninsured Issue Brief :1-21

Zuckerman S, Holahan J. 1988. Pps waivers: Implications for medicare, medicaid, and commercial insurers. Journal of Health Politics, Policy, and Law 13:663-681 


\section{Tables and Figures}

Figure 1: Cross Country Per Capita Health Spending Relative to GDP, 2010

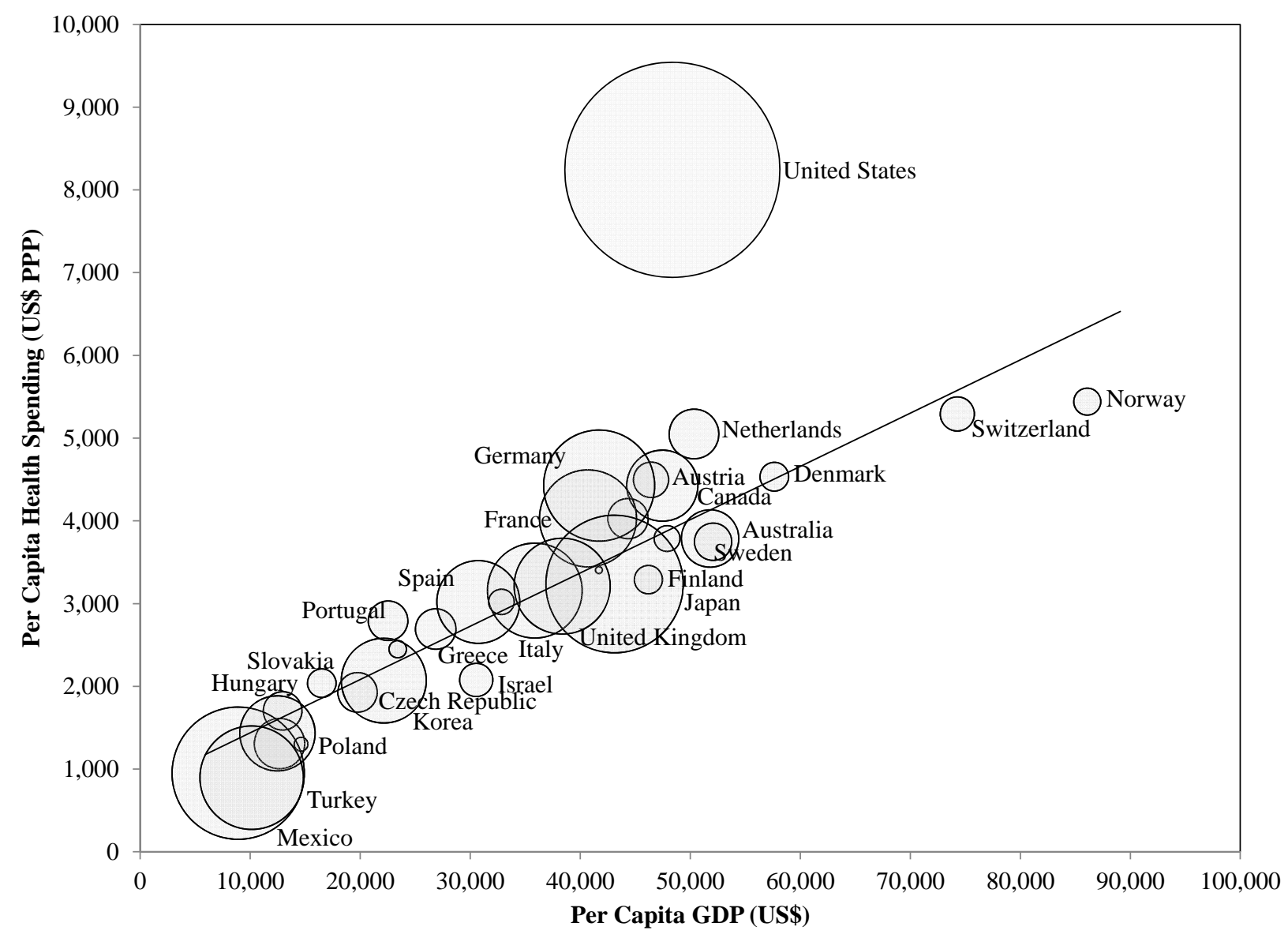

Notes: Per capita health expenditures from OECD Stats Extract. Per capita GDP from World Bank's World Development Indicators. Population from World Health OrganizationâĂŹs Global Health Observatory Data Repository. Circle sizes represent the population count. The line is a fitted linear line that excludes the US. All OECD countries, except for Luxembourg, are shown. 
Figure 2: Health Expenditures as a Percent of GDP, 1960-2013

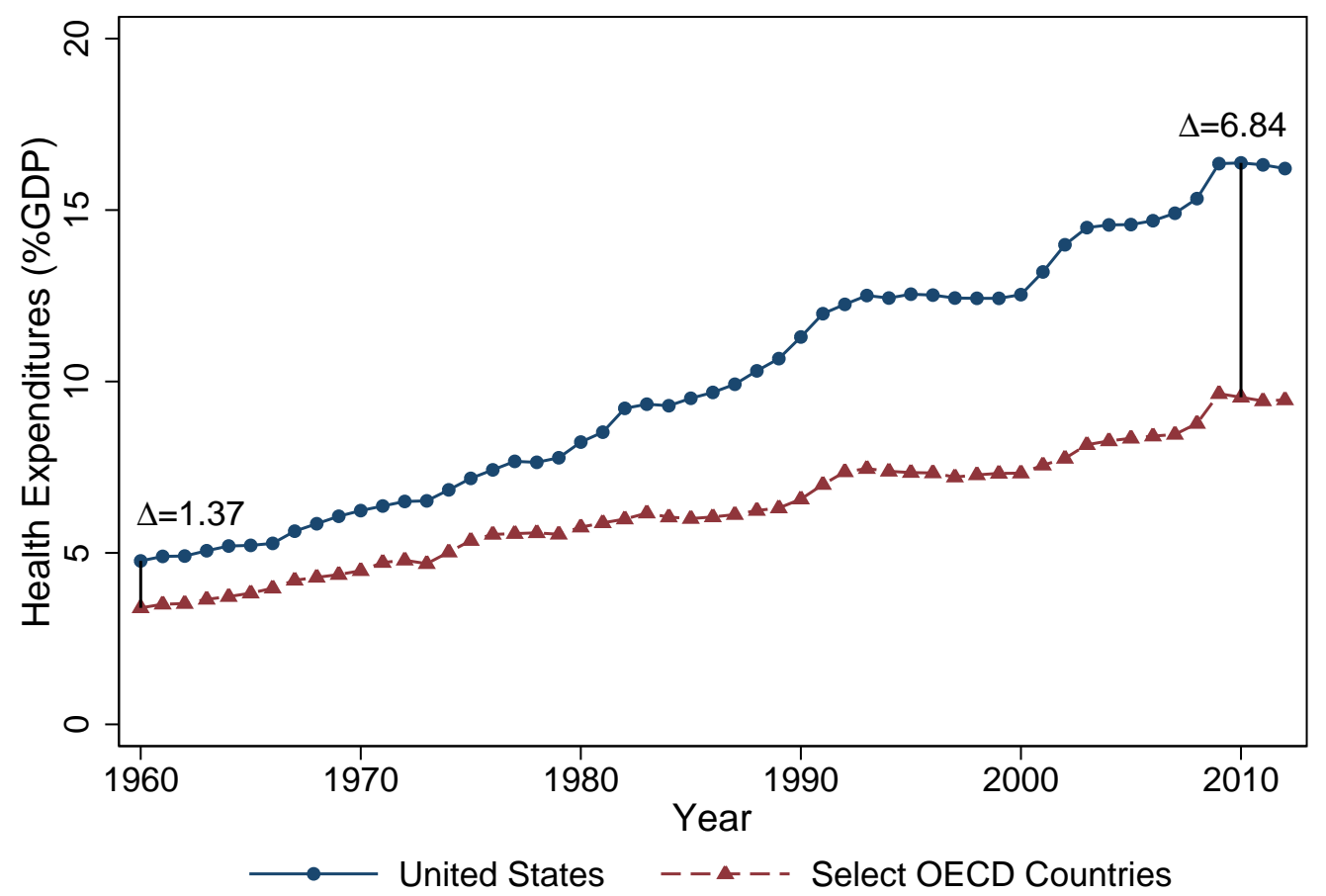

Notes: Data from OECD Health Statistics. "Select OECD Countries" is a population weighted average of data from Austria, Canada, Finland, Ireland, Spain, Switzerland, and the United Kingdom. The other excluded OECD countries do not have available historical data from 1960. Trends from 1990 onwards using all OECD countries are similar to the above graph. 
Figure 3: Percent Change in Health Expenditures, 1960-2013

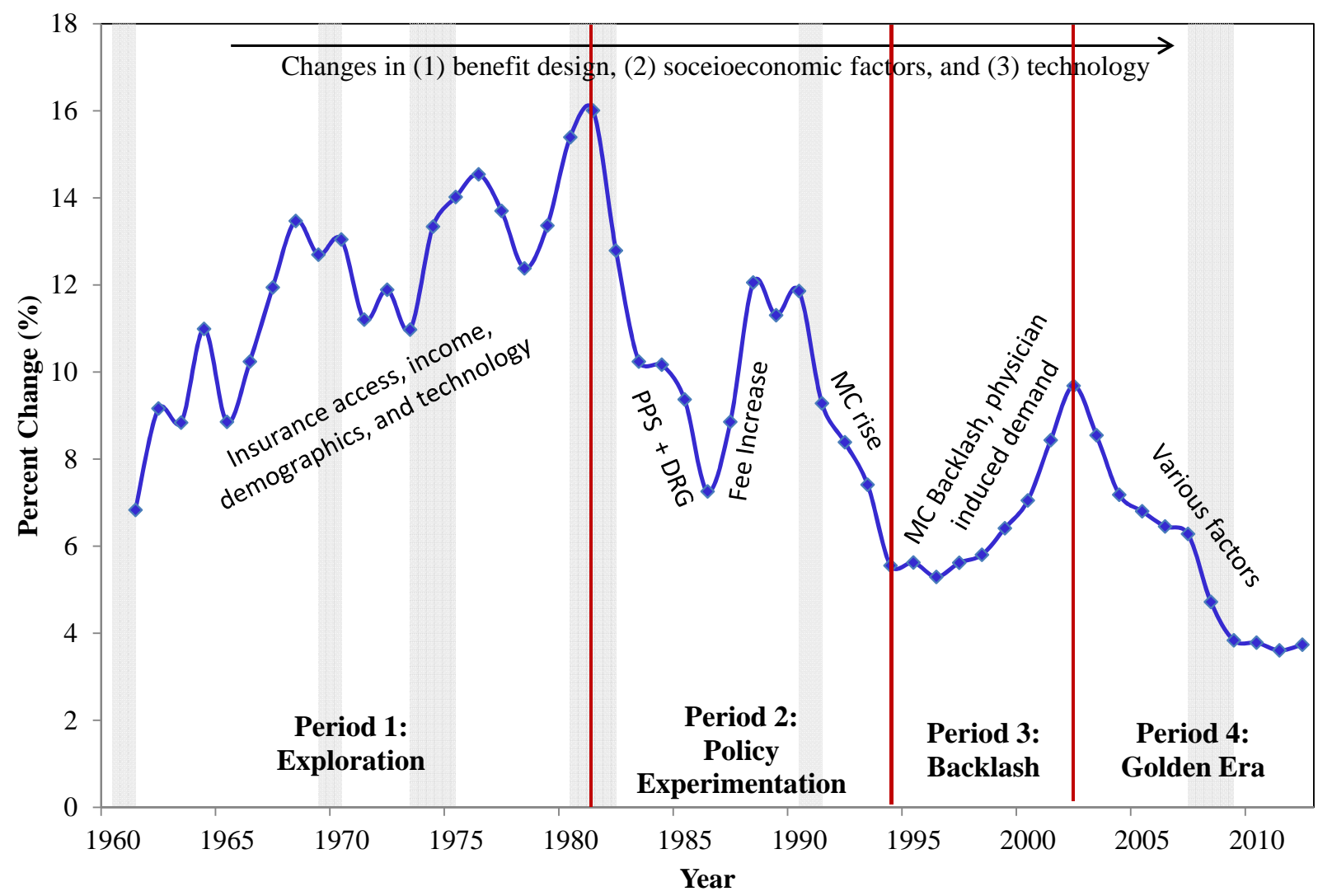

Notes: Data on total annual health spending from the National Health Expenditure Accounts. Grey bars represent macroeconomic recessions as identified by the National Bureau of Economic Research. Changes in benefit design, socioeconomic factors, and technology play a key role throughout this time period. In period 1, the general increase in health expenditure growth can be attributed to increased insurance access, higher income, an aging population, and technological improvements. In period 2, changes in health expenditures are driven by the introduction of Medicare's prospective payment system (PPS), the establishment of diagnosis-related groups (DRG), Medicare's fee increases, and the rise of managed care (MC). In period 3, there was backlash against the managed care system and several studies began to investigate the idea of physician induced demand. In period 4, various factors discussed in Section 5 have contributed to the slowing of health expenditure growth. 
Table 1: Most-Cited Studies Pertaining to Persistent Trends or Trends Specific to 1960-1994 (Periods 1 and 2)

\begin{tabular}{|c|c|c|}
\hline Paper & Study Period & Citation Count \\
\hline \multicolumn{3}{|c|}{ Period 1: Exploration, 1960-1981 and Continuing Trends } \\
\hline \multicolumn{3}{|c|}{ Access to insurance } \\
\hline Manning et al. (1987) & 1974-1977 & 1965 \\
\hline Pauly (1968) & $1968 *$ & 1662 \\
\hline Pauly (1974) & $1974 *$ & 735 \\
\hline Goldman et al. (2007) & $1985-2006$ & 478 \\
\hline \multicolumn{3}{|l|}{ Technology and quality of care } \\
\hline Newhouse (1992) & $1950-1990$ & 1168 \\
\hline Fisher et al. (2003a) & 1993-1995 & 1270 \\
\hline Fisher et al. (2003b) & 1993-1995 & 1065 \\
\hline Weisbrod (1991) & $1940-1990$ & 835 \\
\hline Cutler \& McClellan (2001) & 1984-1998 & 783 \\
\hline Hall \& Jones (2007) & $1950-2000$ & 503 \\
\hline Cutler et al. (2006) & $1960-2000$ & 323 \\
\hline \multicolumn{3}{|l|}{ Socioeconomic factors } \\
\hline Finkelstein et al. (2009) & $1998-2006$ & 1676 \\
\hline Hoffman et al. $(1996)$ & $1987-1990$ & 1044 \\
\hline Schneider \& Guralnik (1990) & 1976-1987 & 774 \\
\hline Newhouse (1977) & $1968-1973$ & 693 \\
\hline Spillman \& Lubitz (2000) & 1974-1996 & 376 \\
\hline Lakdawalla et al.(2004) & $1984-2000$ & 239 \\
\hline
\end{tabular}

\section{Period 2: Policy Experimentation, 1981-1994}

PPS and Medicare DRG

Coulam \& Gaumer (1992) 1983-1988 223

Managed care and technology

Miller \& Luft (1994) 1980-1993 798

Miller \& Luft (1997)

Woolhandler \& Himmelstein (1991) 1987-1988 437

Glied (2000) 1980-1993 340

Physician-induced demand

\begin{tabular}{|lcl|}
\hline McGuire (2000) & $2000^{*}$ & 714 \\
\hline Ellis \& McGuire (1993) & $1984-1990$ & 333 \\
\hline Cromwell \& Mitchell (1986) & $1969-1976$ & 258 \\
\hline Rice (1983) & $1976-1978$ & 238 \\
\hline
\end{tabular}

Notes: In each category, we list the most highly cited papers that pertain to explaining health expenditure trends over time. We consider only studies with (1) at least 200 citations, (2) empirical analyses or publication dates during the time-periods specified each section heading, and (3) more citations than other papers within a broad topic area. * indicates a theory paper. Citation counts are recorded as of August 1, 2015. 
Figure 4: Global Changes in the Excess Health Spending Growth Rate, 1971-2013

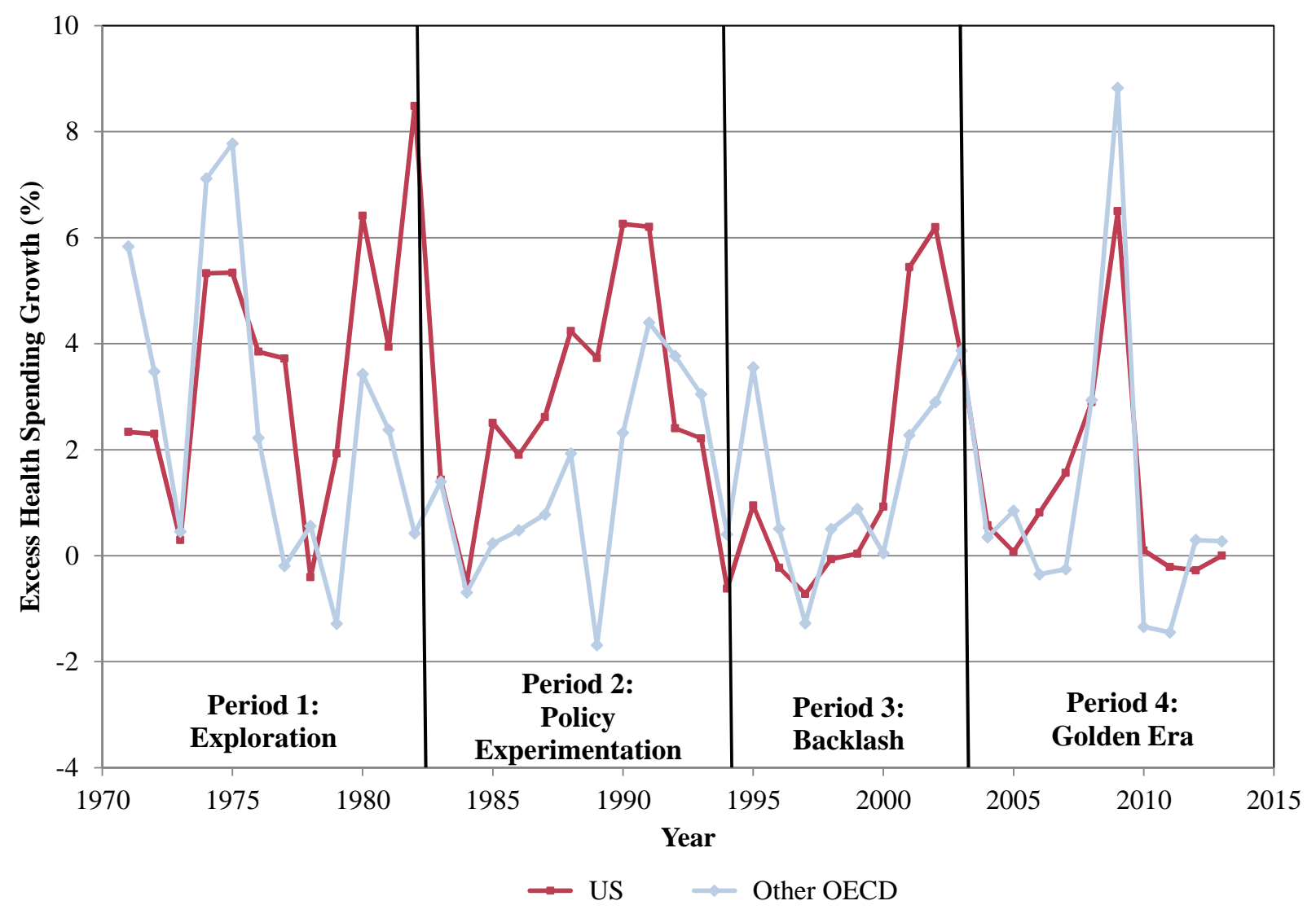

Notes: Following Squires (2014), we define the excess health spending growth as the annual growth rate in health expenditures that exceeds the annual growth rate in GDP. Data is from OECD Statistics. Due to the sparsity of data in 1960, we truncate the graph to examine 1971 to 2013 . Only countries with annual data from 1970 are included. The US excess spending growth (maroon) is compared to a population-weighted average of excess spending growth in other OECD countries (light blue), which include Austria, Canada, Czech Republic, Finland, France, Germany, Ireland, Norway, Portugal, Spain, Switzerland, and the United Kingdom. This figure illustrates that changes in excess spending is similar across all countries. The largest deviation between the US and other OECD countries is during the policy experimentation period. 
Table 2: Most-Cited Studies Pertaining to Trends Specific to 1994-2013 (Periods 3 and 4)

\begin{tabular}{|c|c|c|}
\hline Paper & Study Period & Citation Count \\
\hline \multicolumn{3}{|l|}{ Period 3: Backlash, 1994-2002 } \\
\hline \multicolumn{3}{|l|}{ Manged care backlash } \\
\hline Robinson (2001) & $2001^{\dagger}$ & 279 \\
\hline Blendon et al. (1998) & 1995-1997 & 267 \\
\hline \multicolumn{3}{|l|}{ Period 4: Golden Era, 2002-2015 } \\
\hline \multicolumn{3}{|c|}{ Recession, Medicare, efficiency, technology } \\
\hline Catlin et al. (2008) & 2000-2006 & 202 \\
\hline Truffer et al. $(2010)$ & 2007-2009 & 180 \\
\hline Sisko et al. (2009) & $1993-2008$ & 147 \\
\hline Martin et al. (2014) & 2002-2009 & 107 \\
\hline Chernew et al. (2009) & $2003-2007$ & 74 \\
\hline Cutler \& Sahni (2013) & $2007-2012$ & 39 \\
\hline Ryu et al. (2013) & $2009-2011$ & 33 \\
\hline Holahan \& McMorrow (2013) & $2000-2010$ & 4 \\
\hline
\end{tabular}

Notes: See notes to Table 1. In the more recent period from 2002-2013, we relax the constraint that studies need to have at least 200 citations, and we focus on US-specific analyses. ${ }^{\dagger}$ indicates a descriptive study. Citation counts are recorded as of August 1, 2015.

Table 3: Ten Largest Declines in the Annual Health Expenditure Growth Rate

\begin{tabular}{lcccc}
\hline Rank & Period & $\Delta$ Growth Rate $(\%)$ & period & Recession? \\
\hline 1. & $1981-1982$ & -3.22 & 2. Policy Experimentation & $\mathrm{Y}$ \\
2. & $1990-1991$ & -2.58 & 2. Policy Experimentation & $\mathrm{Y}$ \\
3. & $1982-1983$ & -2.55 & 2. Policy Experimentation & \\
4. & $1964-1965$ & -2.14 & 1. Exploration & \\
5. & $1985-1986$ & -2.11 & 2. Policy Experimentation & \\
6. & $1993-1994$ & -1.86 & 2. Policy Experimentation & \\
7. & $1970-1971$ & -1.84 & 1. Exploration & \\
8. & $2007-2008$ & -1.53 & 4. Golden Era & $\mathrm{Y}$ \\
9. & $2003-2004$ & -1.39 & 4. Golden Era & \\
10. & $1977-1978$ & -1.32 & 1. Exploration & \\
\hline
\end{tabular}

Notes: Data from the National Health Expenditure Accounts. This table shows the 10 largest declines in the annual percent change in health expenditures and whether the decline corresponded with a recession. 


\section{Glossary of Health-Related Acronyms}

\begin{tabular}{ll}
\hline Abbreviation & Definition \\
\hline \hline ACO & Accountable care organization \\
CDHP & Consumer directed health plan \\
CMS & Centers for Medicare and Medicaid Services \\
DRG & Diagnosis related group \\
FFS & Fee-for-service \\
HCFA & Health Care Financing Administration \\
HMO & Health maintenance organization \\
MC & Managed care \\
PPO & Preferred provider organization \\
PPS & Prospective payment system \\
SCHIP & State Children's Health Insurance Program \\
VBID & Value-based insurance design \\
\hline
\end{tabular}

